\title{
Outbreak
}

\section{Outbreak of cutaneous anthrax in Musalimadugu village, Chittoor district, Andhra Pradesh, India, July-August 2011}

\author{
Ramesh Reddy ${ }^{1,3}$, Geetha Parasadini ${ }^{2}$, Prasada Rao ${ }^{2}$, Chengappa K. Uthappa ${ }^{3}$, \\ Manoj V. Murhekar ${ }^{1}$ \\ ${ }^{1}$ Field Epidemiology Training Programme (FETP), National Institute of Epidemiology, Chennai, India \\ ${ }^{2}$ Directorate of Health and Family Welfare, Hyderabad, Andhra Pradesh, India \\ ${ }^{3}$ SHARE India, Hyderabad, Andhra Pradesh, India
}

\begin{abstract}
Introduction: In August 2011, Chittoor district authorities reported a cluster of suspected human anthrax cases to the Andhra Pradesh state surveillance unit. We investigated this cluster to confirm its etiology, describe its magnitude, identify potential risk factors, and make recommendations for preventing similar outbreaks in the future.

Methodology: Suspected cutaneous anthrax was defined as a painless skin lesion (papule, vesicle, or eschar) that appeared in a resident of Musalimadugu between July and August 2011. Clinical details and smears from skin lesions from suspected cases were collected to describe the outbreak by time, place and person. A retrospective cohort study among villagers aged $\geq 15$ years was conducted to identify risk factors for acquiring the infection.

Results: Sixteen livestock in the village died between 24 June and 7 August 2011. Smears from five animals showed Gram-positive, spore bearing characteristics of Bacillus anthracis. Villagers butchered and skinned the dead animals, sold the skin, and consumed the meat after boiling it for two hours. The outbreak in humans started on $30 \mathrm{July}$, and nine suspected cases of cutaneous anthrax (attack rate: $2 \%$, no deaths) occurred until 7 August. The attack rate was higher among those aged $\geq 15$ years. All the smears were negative on Gram staining. Individuals, who had handled, skinned, and slaughtered dead livestock were at higher risk of infection.

Conclusions: We recommend ciprofloxacin prophylaxis to close family contacts. Vaccination of the livestock in the area and community education on the dangers of handling and slaughtering dead/ill livestock are necessary.
\end{abstract}

Key words: cutaneous Anthrax; outbreak; India

J Infect Dev Ctries 2012; 6(10):695-699.

(Received 13 March 2012 - Accepted 23 May 2012)

Copyright ( 12012 Reddy et al. This is an open-access article distributed under the Creative Commons Attribution License, which permits unrestricted use, distribution, and reproduction in any medium, provided the original work is properly cited.

\section{Introduction}

Anthrax is a zoonotic disease that primarily affects herbivores. It is caused by spore-forming, Grampositive bacteria called Bacillus anthracis. Spores are present in contaminated soils and contaminated animal products. Herbivores acquire infection while grazing and may develop septicemia. After their death, the vegetative form of the bacteria is present in the meat and body fluids and the spores may be present on the hides. Carcasses and remains may contaminate soils. In humans, the disease manifests itself in three forms: cutaneous, pulmonary, and intestinal. Cutaneous anthrax accounts for $95 \%$ of the cases [1,2]. Handling contaminated meat, hides, or skins may lead to inoculation of the vegetative form or spores through cuts and abrasions and cause the cutaneous form. Heating at $100^{\circ} \mathrm{C}$ for 10 to 60 minutes kills spores and the vegetative form $[1,2]$.
Global estimates of disease burden are not given for anthrax as WHO considers that the disease is not a major public health problem in the world today, although occasional epidemics occur [2]. In India, many states are enzootic for animal anthrax with human anthrax cases, either sporadic or as small clusters, reported from several states, including Jammu and Kashmir, Orissa, Andhra Pradesh, Tamilnadu and West Bengal [3]. There is no nationally organized control programme in the country as occurrence of disease is focal, affecting only a small number of districts. As a consequence, human anthrax is not a notifiable disease and many disease clusters are not investigated systematically.

On 2 August 2011, the District Medical and Health Officer (DM\&HO) of Chittoor district in Andhra Pradesh informed the state surveillance unit about a cluster of suspected human anthrax cases in 
Figure 1. Distribution of cutaneous anthrax cases by date of reporting, Musalimadugu village, Andhra Pradesh, 2011

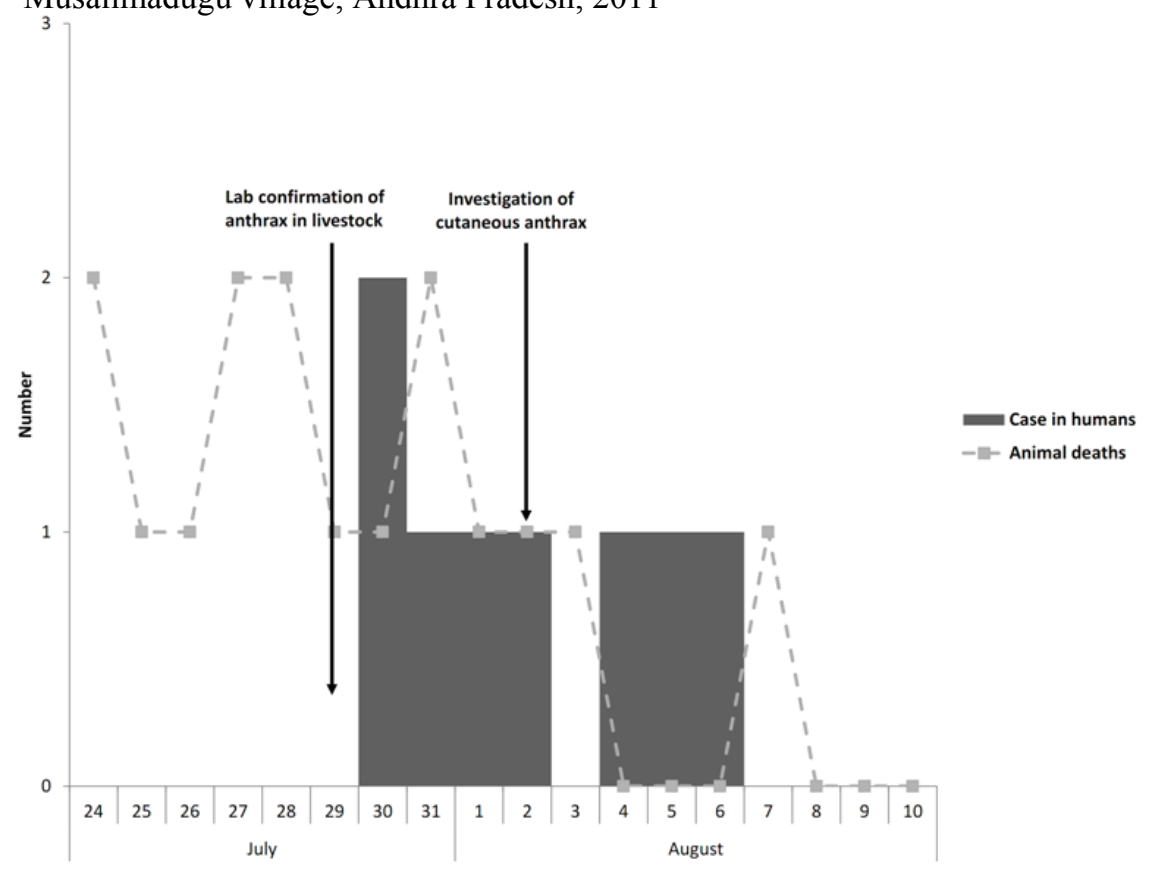

Musalimadugu village (population $=377$ ). The outbreak was preceded by death of livestock in the area. We investigated this cluster with the objectives of (1) confirming the etiology, (2) estimating the magnitude, (3) treating patients, and (4) proposing recommendations to control the present outbreak and prevent future occurrences.

\section{Methodology}

\section{Descriptive epidemiology}

Case definition and data collection: A suspected case of cutaneous anthrax was defined as the occurrence of a painless skin lesion (papule, vesicle or eschar) among the residents of Musalimadugu village of Chittoor district since July 2011. Trained community health workers actively searched for suspected cases by visiting house to house visit. The population was enumerated and information on age, sex, date of onset, and signs and symptoms was collected from all the case-patients. Villagers were interviewed about their exposure to dead or sick animals and women for their cooking practices.

Laboratory investigations: Smears were collected from the skin lesions of five suspected case-patients and transported to the district public health laboratory. The laboratory at the Microbiology Department in the Sri Venkateshwara Institute of Medical Sciences,
Tirupati, stained the smears using Gram stain and examined them microscopically.

\section{Data analysis}

Age and sex specific attack rates were calculated by dividing the number of cases by the enumerated population size and an epidemic curve was plotted to describe the distribution of cases by time and to draw a spot map to know the distribution of the cases.

\section{Analytical epidemiology}

Data collection: A retrospective cohort study among the residents of the village older than 14 years was conducted. Family members were interviewed using structured standardized questionnaires written in Telugu, the local language, to collect information regarding demographics and history of possible exposures, including (1) slaughtering animals, (2) handling meat, (3) eating the meat of a dead animal (4) skinning, (5) carrying dead animals, and (6) handling sick animals during July and August 2011. Relative risk (RR) and 95\% confidence interval (CI) of anthrax associated with potential risk factors using Epi-Info software version 6 (CDC, Atlanta, USA) were calculated. We also calculated the fraction of cases attributable to selected exposures in the population by multiplying the proportion of cases exposed by [(relative risk -1$)$ / relative risk], the attributable 
Table 1. Incidence of cutaneous anthrax by age and sex, in Masilimadugu village, Chittoor, Andhra Pradesh, India, 2011

\begin{tabular}{lrrrr}
\multicolumn{2}{c}{ Characteristics } & Cases & Population & Attack rate per 100 \\
\hline Age & $\mathbf{0 - 1 4}$ & $\mathbf{0}$ & $\mathbf{4 9}$ & 0 \\
& $\mathbf{1 5 - 4 4}$ & 6 & 222 & 3 \\
& $\mathbf{4 5 - 6 4}$ & 2 & 89 & 2 \\
& $\mathbf{6 5 - 8 4}$ & 1 & 16 & 6 \\
& $\mathbf{8 5 5}$ & 0 & 1 & 0 \\
\hline Sex & Male & 5 & 201 & 2 \\
& Female & 4 & 176 & 2 \\
\hline Total & & 9 & 377 & 2 \\
\hline
\end{tabular}

Table 2. Risk of cutaneous anthrax according to selected exposures, in Masilimadugu village, Chittoor, Andhra Pradesh, India, 2011

\begin{tabular}{|c|c|c|c|c|c|c|c|c|}
\hline \multirow[t]{2}{*}{ Variables } & \multicolumn{3}{|c|}{ Risk among exposed } & \multicolumn{2}{|c|}{$\begin{array}{l}\text { Risk } \\
\text { unexposed }\end{array}$} & \multirow{2}{*}{\begin{tabular}{|} 
among \\
$\%$ \\
\end{tabular}} & \multirow[t]{2}{*}{ RR (95\% CI ) } & \multirow[t]{2}{*}{ PAR\% } \\
\hline & \# & $\mathbf{N}$ & $\%$ & \# & $\mathbf{N}$ & & & \\
\hline Female sex & 4 & 171 & 2.3 & 5 & 157 & 3.2 & $1(0.2-2.7)$ & \\
\hline Slaughtered dead animal & 4 & 12 & 33.3 & 5 & 316 & 1.6 & $21(6.5-68.7)$ & \\
\hline Skinned dead animal & 5 & 14 & 35.7 & 4 & 314 & 1.3 & $28(8.4-93.1)$ & $42.3(9.2-75.1)$ \\
\hline Buried dead animal & 8 & 44 & 18.2 & 1 & 284 & 0.4 & $52(6.6-402.9)$ & $53.6(20.1-87.1)$ \\
\hline Ate meat of dead animal & 9 & 200 & 4.5 & 0 & 128 & 0.0 & Undefined & \\
\hline Handled sick animals & 7 & 71 & 9.9 & 2 & 257 & 0.8 & $13(2.7-59.7)$ & $87.2(63.5-100)$ \\
\hline Handled dead animals & 8 & 41 & 19.5 & 1 & 287 & 0.3 & $56(8.4-571.8)$ & $71.6(37.2-100)$ \\
\hline
\end{tabular}


fraction among exposed. We protected the confidentiality of participants through codes and obtained oral consent before conducting the interviews. The investigation was exempted from ethical committee clearance since it was part of the state level public health response to the outbreak.

\section{Results}

Descriptive epidemiology

We identified 9 suspected cases of cutaneous anthrax from a population of 377 persons (attack rate: $2.4 \%$, no deaths). The outbreak started on 30 July 2011, sustained all through the week, and ended on 7 August 2011 (Figure 1). Prior to the outbreak, nine livestock (four cows, two goats, one buffalo, and two calves) in the village died during the period of 24 June 2011 to 29 August 2011 (Figure 1). Cases of cutaneous anthrax were scattered throughout the village. The attack rate was similar among males and females and was higher in those aged 15 years or over (Table 1). On microscopic examination, none of the five skin smears examined had Gram-positive, spore bearing, bacillus characteristic of Bacillus anthracis. Blood smears from three dead animals on methylene blue staining showed spore bearing, bacillus characteristic of Bacillus anthracis.

Persons who slaughtered the dead animals were reported to be butchers. The meat of the dead animals was distributed in the neighbouring households. The individuals who slaughtered the animals or distributed the meat used their bare hands and did not wear any protective equipment. Two individuals involved in skin trading carried the skin to the market in the nearby village for trading. Women in the village reported that they boiled the meat for more than one hour while cooking.

\section{Analytical epidemiology}

We included 328 persons aged 15 years or more from all the 125 families in the village in the cohort study. Their median age was 35 years and $52 \%$ were female. Compared with others, persons who had handled dead animals (RR: 56, 95\% CI: 8.4 - 571) were at a higher risk of illness. People who skinned (RR: 28, 95\% CI: 8.4-93) and slaughtered (RR: 21, 95\% CI: 6.5-68.4) the dead animals were also at a higher risk (Table 2). A substantial proportion of the population was engaged in slaughtering and skinning (33\% and 36\%, respectively) animals. Handling and burying dead animals accounted for the larger proportion of cases (PAF: 87\%) followed by skinning
(PAF: 54\%), while handling sick animals accounted for $72 \%$ of cases.

\section{Discussion}

An outbreak of cutaneous anthrax, associated with exposure to dead livestock including handling, burying, skinning, and slaughtering, occurred in Chittoor district of Andhra Pradesh. As an immediate control measure, we recommended ciprofloxacin prophylaxis to contacts exposed to handling, burying, consuming, and/or skinning of dead or sick livestock [2].

During this outbreak delayed reporting of the death of livestock prevented effective public health response. The outbreak initially started in the livestock and there was a delay of five days in diagnosis. The delay in reporting was primarily caused by nonreporting of animal deaths to the district veterinary department since the animals were not insured. Information about the death of an animal was first reported to the Veterinary Department six days after the outbreak among the livestock. As the index cow was insured, a certificate of death from the Veterinary Department was required to claim the insurance and hence the case was reported. Based on the clinical features and the microscopic examination, death in animals was confirmed to be due to anthrax. After establishing the diagnosis, the district Veterinary Department instructed the villagers not to consume the meat of the dead animals and to report to the veterinary Department any deaths or sick animals in the village. However, by this time the cases of cutaneous anthrax had started occurring in the village because of exposure to dead livestock. If the event of livestock deaths had been reported early, control measures such as abstaining from slaughtering ill animals, decontamination of remains, and vaccination of animals would have commenced early in the area [2].

Slaughtering of ill/dead livestock, handling of raw meat and/or sick animals, and burial of dead livestock in the absence of personal protection measures accounted for the majority of cases during this outbreak. Other studies in India also reported that these practices were the key modes of acquisition of cutaneous anthrax [4-7]. In the case of cutaneous anthrax, the agent present in the meat is usually inoculated through injured skin of persons who come in direct contact with it [2]. No case of intestinal anthrax was reported during the outbreak. Further, there was no evidence that eating the meat of dead animals cooked through prolonged boiling per the 
local recipe caused cutaneous anthrax. Epidemiological studies suggest that consumption of cooked, contaminated meat is not a risk factor for cutaneous anthrax $[7,9]$. Cooking $\left(100^{\circ}-150^{\circ} \mathrm{C}\right.$ for 10 to 60 minutes) sterilizes raw animal materials that may then be consumed safely $[2,4]$.

Our investigation had certain limitations. We were unable to document laboratory diagnosis of anthrax among the human cases reported possibly because the skin smears were collected after an interval of 3 to 5 days of occurrence of symptoms and all the patients were administered antibiotics. However, death of livestock in the village due to anthrax prior to the outbreak in humans, and a strong association between exposure to dead livestock and development of characteristic cutaneous lesions, indicated that the outbreak was caused by anthrax.

During this episode, late notification delayed public health action, leading to additional cases and animal deaths that could have been prevented. This delayed notification was due to a lack of knowledge of the disease among community health care workers. Failure to use personal protection while slaughtering animals, handling meat, and handling skins were the main modes of transmission. The local practice of prolonged boiling of the meat before consumption may have prevented cases of intestinal anthrax.

These conclusions point to a number of recommendations. First, we need to educate the community members to use personal protective equipment including gumboots, gloves, and aprons while slaughtering dead animals and handling meat and skins. Second, we also need to educate the community members as well as health workers in districts where the disease may occur, focusing on recognizing the disease and reporting it promptly. Early reports of animal cases would allow secondary prevention measures, including (a) decontamination of slaughtering sites, (b) surveillance of animals, (c) advice to avoid slaughtering ill and dead livestock, and (d) vaccination of herbivores. Collaboration with the Animal Husbandry Department would increase the effectiveness of such measures [10]. India does not have a nationally organized control programme as occurrence is focal, affecting only a few districts. In such districts, a prevention plan based on these recommendations would ultimately help in reducing the morbidity and mortality due to anthrax.

\section{References}

1. World Health Organization (2005) The control of neglected zoonotic diseases: a route to poverty alleviation: report of a joint WHO/DFID-AHP meeting, 20 and 21 September 2005, WHO Headquarters, Geneva, with the participation of FAO and OIE. http://www.who.int/zoonoses/Report_Sept06.pdf. Accessed 19 September 2012.

2. World Health Guidelines for the Surveillance and Control of Anthrax in human and animals. 3rd edition. http://www.who.int/csr/resources/publications/anthrax/WHO EMC_ZDI_98_6/en/. Accessed 18 September 2012.

3. Thappa DM, Karthikeyan K (2001) Anthrax: an overview within the Indian subcontinent. International journal of dermatology. 40: 216-222.

4. Rao GR, Padmaja J, Lalitha MK, Rao PV, Gopal KV, Kumar HK, Mohanraj P (2005) An outbreak of cutaneous anthrax in a non-endemic district - Visakhapatnam in Andhra Pradesh. Indian J Dermatol Venereol Leprol .71: 102-105.

5. Sekhar PC, Jaya Singh RS, Sridhar MS, Jaya Bhaskar C, Sreehari Rao Y (1990) Outbreak of human anthrax in Ramabhadrapuram village of Chittoor district in Andhra Pradesh. Indian J Med Res. 91:448-452.

6. Lalitha MK and Kumar A (1996) Anthrax: a continuing problem in southern India. Indian Journal of Medical Microbiology. 14: 63-72.

7. Ray TK, Hutin YJ, Murhekar M (2009) Cutaneous anthrax, West Bengal, India, 2007. Emerg Infect Dis 15: 497-499.

8. Morton MS and Arnold NW (2003) Miscellaneous Bacterial Infections with Cutaneous manifestations. In: Freedberg IM, Eisen AZ, Wolff K, Austen KF, Goldsmith LA, Katz SI, editors. Fitzpatrick's, Dermatology in General Medicine. 6th Ed. New York: McGraw-Hill. p. 1918-1921.

9. Woods CW, Ospanov K, Myrzabekov A, Favorov M, Plikaytis B, Ashford DA (2004) Risk factors for human anthrax among contacts of anthrax-infected livestock in Kazakhstan. Am J Trop Med Hyg 71: 48-52.

10. Chakraborty A, Khan SU, Hasnat MA, Parveen S, Islam MS, Mikolon A, Chakraborty RK, Ahmed BN, Ara K, Haider N, Zaki SR, Hoffmaster AR, Rahman M, Luby SP, Hossain MJ (2012) Anthrax outbreaks in Bangladesh, 2009-2010. Am J Trop Med Hyg 86: 703-710.

\section{Corresponding author}

M. V. Murhekar

R-127, Tamilnadu Housing Board

Ayapakkam, Chennai-600 077

Tamilnadu, India

Telephone: 91-44-2635 7517

Fax: 91-44- 26357464

Email: directorne@dataone.in

Conflict of interests: No conflict of interests is declared. 